03

\title{
Исследование оптических и плазмонных особенностей в спектрах отражения слоев наночастиц серебра, осажденных из раствора $\mathrm{AgNO}_{3}$ на поверхности кремния
}

\author{
(C) В.А. Толмачев, Ю.А. Жарова, С.А. Грудинкин \\ ФТИ им. А.Ф. Иофрфе, \\ 194021 Санкт-Петербург, Россия \\ e-mail: tva@mail.ioffe.ru
}

Поступила в редакцию 02.08.2020 г.

В окончательной редакции 02.08.2020 г.

Принята к публикации 14.08.2020 г.

Для интерпретации спектров отражения слоев $\mathrm{Ag}$ на подложке кремния использован подход с применением расчета спектров отражения $\mathrm{R}_{\text {calc }}$ тонкой пленки при варьировании толщины, в результате которого отслеживается влияние критических точек подложки c-Si в зоне Бриллюэна и формирование характеристик объемного $\mathrm{Ag}$ вблизи края межзонных переходов. Проведено сопоставление $R_{\text {calc }}$ с экспериментальными спектрами $R_{\exp }$ слоев наночастиц $\mathrm{Ag}$ различной морфологии, измеренных при нормальном и наклонном $\left(45^{\circ}\right)$ углах падения света. Для слоя с более крупными наночастицами наблюдается формирование резкого провала на спектре $R_{\exp }$, практически совпадающего с краем межзонных переходов объемного $\mathrm{Ag}$ в УФ диапазоне, а также широкого провала в спектре $R_{\exp }$ с минимумом при $\lambda=382 \mathrm{~nm}$, демонстрирующим максимум поглощения локализованного плазмонного резонанса наночастиц Аg. Для образцов с меньшими

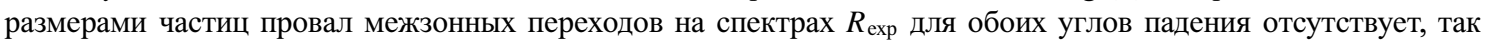
как осажденные наночастицы $\mathrm{Ag}$ не сформировались в структуру с оптическими свойствами объемного $\mathrm{Ag}$, но проявился объемный плазмонный резонанс при $\lambda \sim 335 \mathrm{~nm}$ в продольной моде при наклонном угле падения.

Ключевые слова: кремний, наночастицы серебра, спектры отражения.

DOI: $10.21883 /$ OS.2020.12.50324.211-20

\section{Введение}

Наноплазмоника связана с изучением взаимодействия электронов в металлических средах с оптическим излучением [1-3]. Для целенаправленного создания таких сред (пленок, наночастиц, метаматериалов) необходимо моделирование определенной структуры слоев и наночастиц, а также применение технологических возможностей современной наноиндустрии. Актуальность исследований в этой области обусловлена необходимостью создания различных наноустройств для химических и биологических сенсоров, эффективных преобразователей электромагнитного излучения, в разработках оптических суперкомпьютеров, а также создания плазмонного лазера и его интеграции в фотонные устройства [4].

Серебро благодаря своим оптическим и электронным свойствам является одним из наиболее используемых плазмонных материалов. Оптические свойства $\mathrm{Ag}$ тесно связаны с наличием в структуре связанных и несвязанных зарядов, которые могут возбуждаться в виде объемных плазмонных резонансов, поверхностных плазмонных поляритонов и плазмонных резонансов в наночастицах [1]. Оно химически достаточно стабильно в обычной атмосфере, что позволяет использовать его в создаваемых приборах и устройствах.
Существуют различные способы нанесения нанослоев Ag на подложки: термическое, электронное, магнетронное распыление, химический метод из раствора нитрата серебра и др. Эти методы обеспечивают чистоту химического состава осаждаемого материала и достаточно высокую воспроизводимость процесса. Большая часть экспериментальных работ проводится на подложках из прозрачных материалов (стекло, сапфир, полимеры и др.), что позволяет использовать оптические методы, основанные на пропускании, для определения поглощения, оптической плотности и изучения плазмонных эффектов в синтезируемой структуре [5]. В последние десятилетия благодаря интенсивному развитию микро- и наноэлектроники и технологий массового производства микрочипов наиболее востребованной подложкой оказался монокристаллический кремний. Следует отметить, что $\mathrm{Si}$ поглощает свет в видимой и УФ областях спектра, что затрудняет измерения оптического пропускания. Поэтому для поглощающих подложек применяются методы отражательной спектрофотометрии [6,7] и спектроэллипсометрии [8-11]. Полученная в виде спектров макроскопическая информация может быть использована для описания оптических и плазмонных особенностей наноструктур в рамках различных моделей и определения их микроскопических характеристик. 

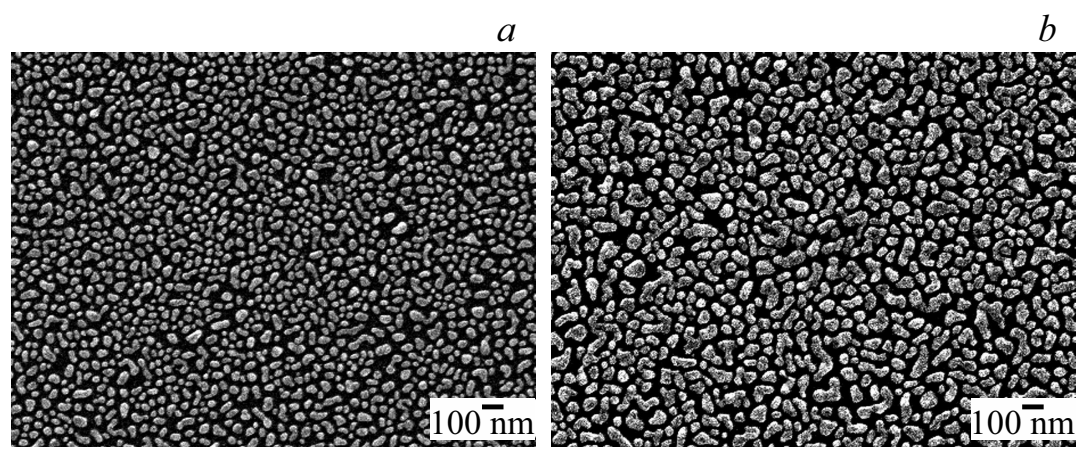

b

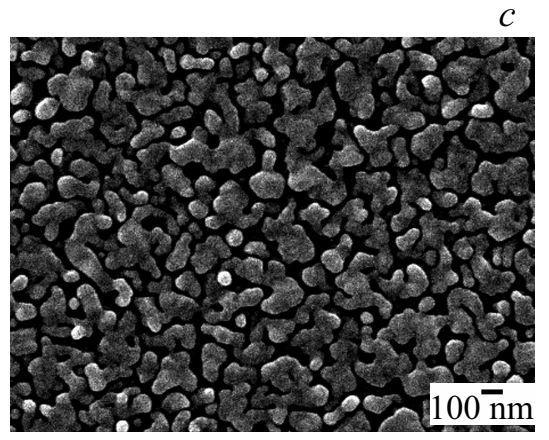

Рис. 1. РЭМ-изображения химически осажденных слоев наночастиц $\mathrm{Ag}$ с разной морфологией на подложке с-Si показаны в одном масштабе (репер геометрических размеров $100 \mathrm{~nm})$. Образец $\mathrm{S} 10\left(d_{\mathrm{Ag}} \sim 16 \mathrm{~nm}\right)(a)$, S5 $\left(d_{\mathrm{Ag}} \sim 23 \mathrm{~nm}\right)(b)$ и $\mathrm{S} 1\left(d_{\mathrm{Ag}} \sim 45 \mathrm{~nm}\right)(c)$.

Целью настоящей работы было охарактеризовать с помощью отражательной спектрофотометрии в УФ и видимой областях при нормальном и наклонном углах падения света оптические и плазмонные особенности слоев наночастиц $\mathrm{Ag}$, химически осажденных на подложку монокристаллического $\mathrm{Si}$, сопоставить их с данными электронной микроскопии и расчетными спектрами для тонких сплошных пленок Ag. Расчет спектров отражения в рамках модели сплошной пленки с плоскопараллельными границами на подложке позволяет по мере роста ее толщины прогнозировать изменения в $R_{\text {calc }}$ : во-первых, в области критических точек диэлектрических функций объемного c-Si; во-вторых, в области края межзонных переходов объемного Ag. Так как эти изменения могут быть связаны с функциями этих материалов, то их можно учитывать в экспериментальных спектрах слоев наночастиц различной морфологии.

\section{Методы эксперимента и расчета}

Слои наночастиц Ag были получены методом химического осаждения из раствора нитрата серебра. Для формирования структур с различной морфологией было выбрано изменение концентрации Ag-содержащего компонента $\mathrm{AgNO}_{3}$ в растворе HF. Обычно перед нанесением металла формируется слой $\mathrm{SiO}_{2}$ для создания электрической изоляции от подложки, но его введение вносит определенный вклад в оптический отклик, что затрудняет интерпретацию получаемых спектров отражения. В настоящей работе этот слой был минимальной толщины $1 \mathrm{~nm}$, определенной с помощью спектрального эллипсометра. Морфология и толщина осаждаемых слоев $\mathrm{Ag}$ исследовалась с помощью растрового электронного микроскопа (РЭМ) JSM-7001F и атомносилового микроскопа. Спектры зеркально отраженного пучка $R_{\exp }$ записывались с помощью спектрофотометра HR4000CG-UV-NIR „Ocean Optics“ для угла, близкого к нормальному $\left(\sim 6^{\circ}\right)$, а также спектрофотометра СФ-56 (ЛОМО, Санкт-Петербург) для угла падения $\varphi=45^{\circ}$. При интерпретации неполяризованных спектров $R_{\exp }$ проводилось их сопоставление с поляризационными ( $p$ и $s)$ спектрами отражения $R_{\text {calc }}$, где $p$ - и $s$-поляризации соответствуют параллельной и перпендикулярной плоскости падения электрического вектора падающей волны соответственно. Расчет проводился в рамках модели слоя с плоскопараллельными границами раздела между воздухом и подложкой с использованием формул Френеля.

\section{Экспериментальная часть}

На исходные пластины Si КДБ (100), $\rho=0.5 \Omega \cdot \mathrm{cm}$ осаждался слой наночастиц серебра из раствора $0.02 \mathrm{M} \mathrm{AgNO}_{3}$ в $5 \mathrm{M} \mathrm{HF}$ с разным соотношением компонентов в растворе (от $1: 1,1: 5$ до $1: 100.02 \mathrm{M} \mathrm{AgNO} 3: 5 \mathrm{M} \mathrm{HF}$ соответственно), время осаждения оставалось постоянным (30 s) [11]. На данных образцах с помощью атомно-силовой микроскопии были измерены толщины островковой пленки серебра путем усредненения по ансамблю частиц их размеров в направлении, перпендикулярном подложке. Эти толщины составили от $16 \mathrm{~nm}$ при соотношении $1: 10$ до $45 \mathrm{~nm}$ при $1: 1$ (рис. 1).

Полученные данные позволяют сделать вывод о том, что осаждение серебра происходит путем зародышеобразования первичных наночастиц серебра на энергетически выгодных центрах. С увеличением концентрации раствора образуются более крупные островки Ag. Далее представлены исследования спектров отражения этих структур методами спектрофотометрии.

\section{Расчетные спектры тонких пленок и экспериментальных слоев наночастиц $\mathrm{Ag}$}

На рис. 2 для слоев наночастиц $\mathrm{Ag}$ видно, что для угла падения $\varphi$, близкого к нормальному, спектры для образцов S5 и S10 аналогичны по форме, тогда как по сравнению с образцом S1 форма $R_{\exp }$ резко отличается. Для интерпретации представленных экспериментальных спектров были рассчитаны спектры $R_{\text {calc }}$ пленки $\mathrm{Ag}$ в 


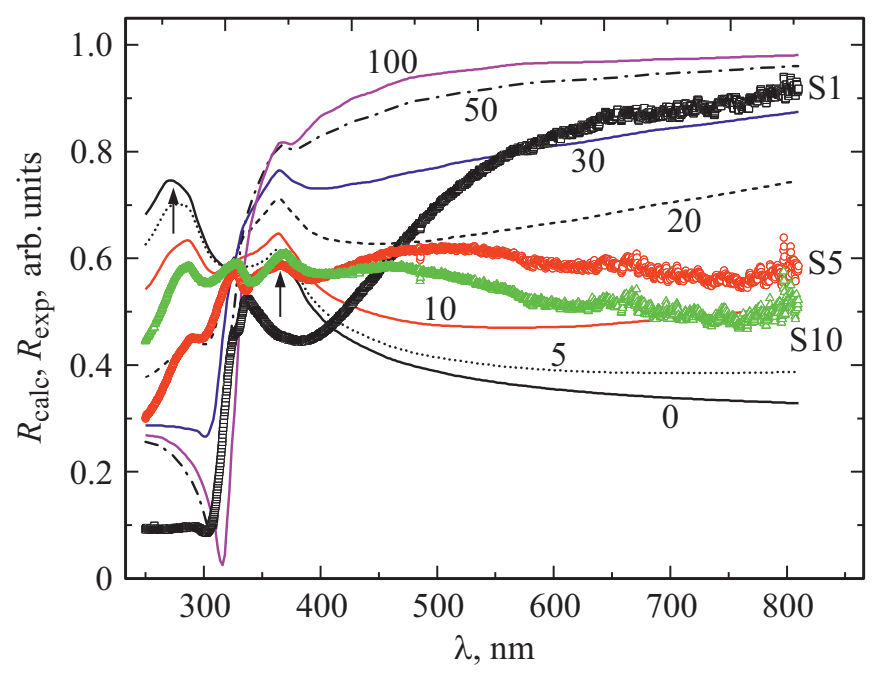

Рис. 2. Экспериментальные спектры отражения $R_{\exp }$ для образцов слоев наночастиц $\mathrm{Ag} \mathrm{S} 1, \mathrm{~S} 5$ и $\mathrm{S} 10$ с различной морфологией из рис. 1 и расчетные $R_{\text {calc }}$ для тонких слоев с диэлектрическими функциями объемного серебра $\mathrm{Ag}_{\mathrm{bulk}}$ с толщиной $d_{\mathrm{Ag}}$ от 0 до $100 \mathrm{~nm}$ (штриховые линии); подложка c-Si, угол нормального падения. Стрелки - положение максимумов $R$ в критических точках $\mathrm{c}-\mathrm{Si}$.

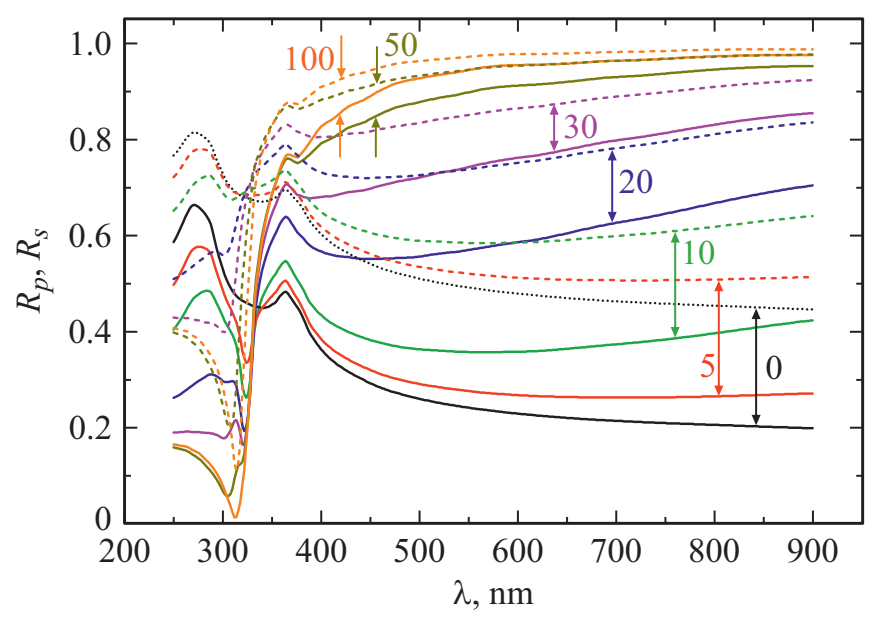

Рис. 3. Расчетные спектры отражения $R_{p}$ (сплошные линии) и $R_{s}$ (пунктир) для тонких слоев с оптическими характеристиками $\mathrm{Ag}_{\text {bulk }}[12]$ и толщиной $d_{\mathrm{Ag}}$ от 0 до $100 \mathrm{~nm}, p$ - и $s$-спектры связаны с помощью стрелок; подложка с- $\mathrm{Si}, \varphi=45^{\circ}$.

рамках тонкослойной модели, чтобы выявить на них оптические особенности и сопоставить с $R_{\exp }$.

\section{Расчетные спектры тонких пленок Ag для нормального угла падения}

Спектры $R_{\text {calc }}$ для тонких сплошных слоев $\mathrm{Ag}$ с оптическими характеристиками для объемного серебра $\left(\mathrm{Ag}_{\text {bulk }}\right)$ из справочника [12], рассчитанные для различных толщин $d_{\mathrm{Ag}}$ в диапазоне от 0 до $100 \mathrm{~nm}$, представлены на рис. 2 в виде штриховых линий. Спектр
$R_{\text {calc }}$ при $d_{\mathrm{Ag}}=0 \mathrm{~nm}$ соответствует $R_{\mathrm{Si}}$ подложки $(\mathrm{c}-\mathrm{Si})$, для которой оптические параметры $(n$ и $k)$ были взяты из справочника [12]. На этом спектре выделяются два максимума при $\lambda_{1}=272 \mathrm{~nm}$ и $\lambda_{2}=365 \mathrm{~nm}$ (отмечены стрелками), которые соответствуют критическим точкам (КТ1 и КТ2) структуры монокристаллического $\mathrm{Si}$ [13]. Сравнивая спектры $R_{\text {calc }}$ для различных $d_{\mathrm{Ag}}$ со спектром $R_{\mathrm{Si}}\left(d_{\mathrm{Ag}}=0 \mathrm{~nm}\right)$, видно, что по мере увеличения $d_{\mathrm{Ag}}$ максимум, обусловленный КТ1, заметно подавляется для спектров слоев с толщинами больше $d_{\mathrm{Ag}}=20 \mathrm{~nm}$, а максимум для КТ2 $(365 \mathrm{~nm})$ сохраняется вплоть до $d_{\mathrm{Ag}}=100 \mathrm{~nm}$, что связано с меньшим коэффициентом поглощения $\mathrm{Ag}$ в этой области спектра по сравнению с областью КТ1. При увеличении $d_{\mathrm{Ag}}$ спектры $R_{\text {calc }}$ трансформируются следующим образом: для $d_{\mathrm{Ag}}=10-20 \mathrm{~nm}$ значение $R$ в УФ области $(250-320 \mathrm{~nm})$ уменьшается, а при $d_{\mathrm{Ag}}=50-100 \mathrm{~nm}$ появляется резкий провал при $\lambda \sim 310 \mathrm{~nm}$, который расположен вблизи края полосы поглощения связанных электронов (межзонных переходов) структуры $\mathrm{Ag}_{\text {bulk. }}$. Значения $R$ в видимой области спектра $(\lambda=400-800 \mathrm{~nm})$ при малых значениях $d_{\mathrm{Ag}}$ увеличиваются и для $d_{\mathrm{Ag}}>50 \mathrm{~nm}$ достигают $R_{\text {calc }}=0.9-0.95$, приближаясь к расчетным значениям для $\mathrm{Ag}_{\text {bulk }}$. Теперь, имея представление, что происходит со спектрами $R_{\text {calc }}$ для сплошной пленки $\mathrm{Ag}$ и как она может подавлять KT c-Si, было проведено их сопоставление с $R_{\text {exp }}$ слоев наночастиц.

\section{Экспериментальные спектры слоев наночастиц Ag}

Для сравнения $R_{\exp }$ с расчетными спектрами первым был выбран спектр для образца S1 (рис. 2), который имеет наибольшую толщину слоя и размеры наночастиц Ag. На этом спектре при $\lambda \sim 310 \mathrm{~nm}$ виден резкий провал значений $R_{\exp }$ от 0.5 до 0.1 , причем его положение практически совпадает с резким провалом $R_{\text {calc }}$ для $\mathrm{Ag}_{\text {bulk }}(\lambda=317 \mathrm{~nm}[12])$, который почти в 2 раза глубже (от 0.8 до 0.1). Этот провал в $R$ и его форма являются проявлением в структуре S1 края межзонных переходов Ag, т.е. оптических свойств, характерных для объемного $\mathrm{Ag}$. Провал в спектре $R_{\exp }$ в области $\lambda<300 \mathrm{~nm}$ скрыл КТ1 подложки, что характерно для $R_{\text {calc }}$ сплошных слоев $\mathrm{Ag}$ с толщиной $d_{\mathrm{Ag}}>30 \mathrm{~nm}$. Пло-

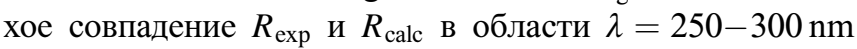
объясняется сильным рассеянием наночастиц в этой области спектра с соответствующим уменьшением $R$ до 0.1 по сравнению с $R_{\text {calc }}$ для тонких пленок $\mathrm{Ag}_{\text {bulk }}$.

В видимой области зависимость $R_{\text {exp }}$ также отличается от спектра $R_{\text {calc }}$ для $\mathrm{Ag}_{\text {bulk }}$ по вышеназванной причине несплошности слоя наночастиц $\mathrm{Ag}$, а наблюдаемый провал с минимумом при $\lambda=382 \mathrm{~nm}$ отражает максимум поглощения, которое обусловлено локализованным плазмонным резонансом (ЛПР) наночастиц $\mathrm{Ag}$ [1]. В литературе представлены экспериментальные результаты в основном по определению оптической плотности в 


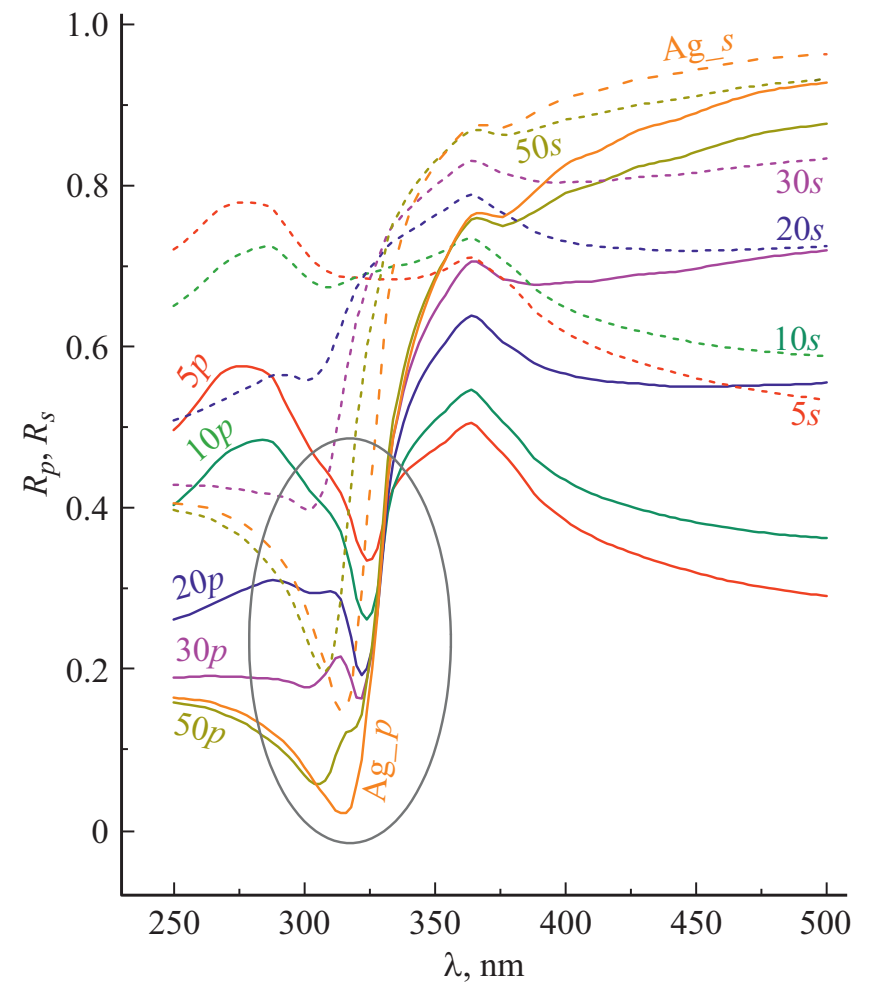

Рис. 4. Расчетные спектры отражения в УФ области для $p$ и $s$-поляризации для слоев $\mathrm{Ag}$ толщиной $d_{\mathrm{Ag}}$ от 5 до $50 \mathrm{~nm}$ и для объемного Ag. Провалы для $p$-спектров выделены овалом; $\varphi=45^{\circ}$.

спектрах Ag слоев на подложках с хорошей прозрачностью (стекло, сапфир, полимеры и др.). Например, в работе [14] собраны данные разных авторов, которые наблюдали плазмонные резонансы островков $\mathrm{Ag}$ в диапазоне от 428 до $550 \mathrm{~nm}$. Публикаций по измерению спектров отражения слоев $\mathrm{Ag}$ на поглощающих подложках не так много, в частности на $\mathrm{Si}$. Так, в работе [6] при расчете поляризованных спектров $R$ для нормально падающего света на наночастицы $\mathrm{Ag} \mathrm{c}$ анизотропией формы на подложке $\mathrm{Si}$ определены два минимума $R$ при $\lambda \sim 340$ и $400 \mathrm{~nm}$ соответственно для двух поляризаций. Наблюдаемое в нашем эксперименте положение минимума $R$ при $\lambda=382 \mathrm{~nm}$ (рис. 2) для неполяризованного света и хаотично расположенных наночастиц находится в близком соответствии с этой работой. Из-за наличия ЛПР в спектре $R_{\exp }$ отсутствует особенность структуры c-Si в виде второго максимума, соответствующего КТ2 $(\lambda=365 \mathrm{~nm})$. Анализируя форму

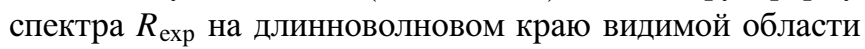
$(600-800 \mathrm{~nm})$, можно отметить плавную зависимость $R$ от длины волны, такую как для объемного $\mathrm{Ag}_{\text {bulk }}$, но по величине меньшую, поскольку она демонстрирует структуру слоев с включением компонента воздуха.

Таким образом, для этого образца S1 структура слоя наночастиц, несмотря на его несплошность, проявляет в УФ области оптические свойства, подобные $\mathrm{Ag}_{\text {bulk }}$, a ближе к видимой области спектра - присутствие локализованного плазмонного резонанса, при этом также наблюдается подавление оптических особенностей (КТ) подложки.

На спектрах $R_{\exp }$ образцов $\mathrm{S} 5$ и $\mathrm{S} 10$, которые близки по форме, в УФ диапазоне видны оптические особенности подложки в виде обеих КТ. Это объясняется небольшой толщиной слоев $\mathrm{Ag}$ (рис. $1, b$ и $1, c$ ), кроме того, и в расчетных спектрах сплошных пленок $\mathrm{Ag}$ для таких же толщин также проявляются эти особенности подложки. Что касается провала на обоих спектрах в области $\lambda=390-400 \mathrm{~nm}$, по его положению, близкому с плазмонному провалу в спектре $R_{\exp }($ при $382 \mathrm{~nm})$ для образца $\mathrm{S} 1$, можно считать, что для обоих образцов S5 и S10 имеет место ЛПР, но менее выраженный, возможно, из-за сильного влияния особенности подложки в этой области спектра в виде КТ2. Следует отметить, что в спектрах обоих образцов нет характерного провала при $\lambda=317 \mathrm{~nm}$, что указывает на отсутствие проявления оптических характеристик $\mathrm{Ag}_{\text {bulk }}$ из-за небольшой плотности осажденных частиц.

Далее представлен анализ спектров для наклонного угла падения сначала для $R_{\text {calc }}$ и затем их сопоставление c $R_{\exp }$.

\section{Спектры отражения тонких пленок $\mathrm{Ag}$ при наклонном угле падения}

Расчетные спектры отражения $R_{\text {calc }}$ для тонких слоев объемного $\mathrm{Ag}$ с толщиной $d_{\mathrm{Ag}}$ от 0 до $100 \mathrm{~nm}$ для двух $p$ - и $s$-поляризаций при угле падения относительно нормали $\varphi=45^{\circ}$ представлены на рис. 3. Видно, что значения $R_{s}$ превышают $R_{p}$, при этом по мере увеличения толщины пленки $\mathrm{Ag}$ различие между ними уменьшается. В области $\lambda=323 \mathrm{~nm}$ для $d_{\mathrm{Ag}}<50 \mathrm{~nm}$ на спектрах $R_{p}$ наблюдается провал, тогда как для $s$-поляризации он отсутствует. Эта особенность более подробно представлена на рис. 4, на котором видно, что положение провала по мере увеличения $d_{\mathrm{Ag}}$ находится недалеко от положения края межзонных переходов при $\lambda=317 \mathrm{~nm}$, которое для объемного $\mathrm{Ag}$ не зависит от поляризации света.

Провал на границе энергии свободных и связанных электронов в структуре тонких пленок Ag был отмечен в экспериментальных спектрах пропускания для $p$-поляризации [15] и позже другими авторами. В работе [16] были сопоставлены и проанализированы зависимости диэлектрических функций $\mathrm{Ag}$, полученных различными авторами. Было отмечено, что в области энергии $E$ выше $4 \mathrm{eV}$ экспериментальные данные хорошо описываются теорией связанных электронов в структуре Ag, а в области до $3 \mathrm{eV}$ (для свободных электронов) - по формуле Друде. Причем сравнение проведено для достаточно разных по способам получения пленок осаждения в вакууме в [17] и путем электрохимического полирования объемного Ag [18]. В свою очередь, для 


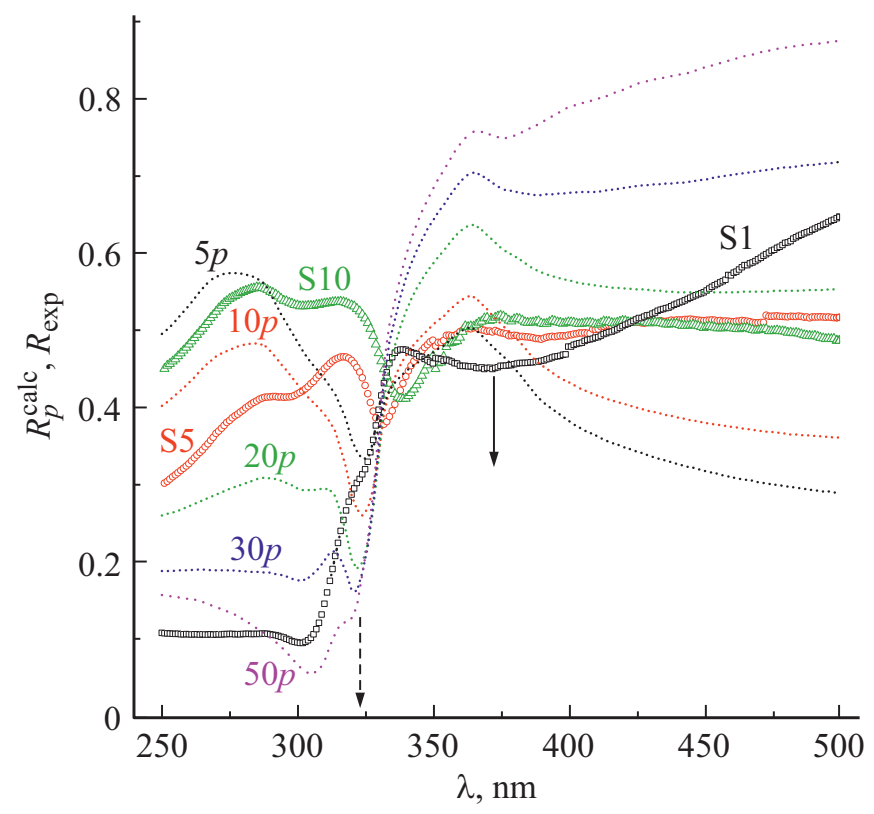

Рис. 5. Экспериментальные спектры отражения $R_{\exp }$ $\left(\varphi=45^{\circ}\right)$ слоев наночастиц $(\mathrm{S} 1, \mathrm{~S} 5, \mathrm{~S} 10)$ (символы) и расчетные $R_{p}^{\text {calc }}$ тонких пленок $\mathrm{Ag}$ (пунктир); стрелка - положение ЛПР слоя наночастиц $\mathrm{Ag}$ (образец $\mathrm{S} 1$ ), штриховая стрелка положение объемного плазмона в продольной моде для расчетных спектров пленок с различными $d_{\mathrm{Ag}}(5-30 \mathrm{~nm})$.

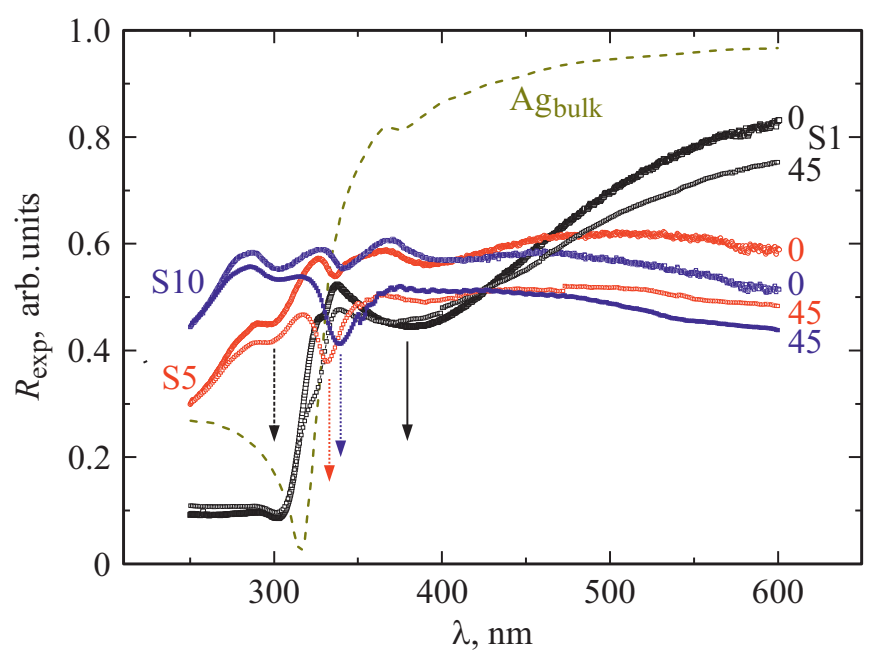

Рис. 6. Сопоставление экспериментальных спектров отражения $R_{\exp }$ образцов $\mathrm{S} 1, \mathrm{~S} 5, \mathrm{~S} 10$ для двух углов падения (0 и $45^{\circ}$, цифры у спектров). Штриховая стрелка - положение края межзонных переходов $\mathrm{Ag}$ в слое наночастиц $\mathrm{S} 1$ и простая стрелка - положение локализованного плазмонного резонанca, пунктирные стрелки - провалы объемного плазмона в продольной моде для наклонного угла падения образцов S5 и S10. Рассчитанный спектр отражения для объемного Ag.

тонкослойных пленок с плоскопараллельными границами раздела неизменность положения провала $R_{p}^{\text {calc }}$ около $\lambda=323 \mathrm{~nm}$ характеризует объемный плазмон для про- дольной моды р-поляризованной волны при наклонном падении света [19].

\section{Экспериментальные спектры отражения слоев наночастиц $\mathrm{Ag}$ при $\varphi=45^{\circ}$}

Аналогично рассмотренному выше случаю практически нормального падения света проведен анализ спектров $R_{\text {exp }}$ слоев наночастиц $\mathrm{Ag}(\mathrm{S} 1, \mathrm{~S} 5, \mathrm{~S} 10)$ путем сопоставления с $R_{p}^{\text {calc }}$, которые представлены на рис. 5 .

Для образца S1 с большей толщиной слоя и поперечными сечениями наночастиц $\mathrm{Ag}$ положение провала $(\lambda=375 \mathrm{~nm})$ в $R_{\exp }$ оказалось близким к ЛПР для нормального угла падения (рис. 2). Разброс размеров и формы наночастиц приводит к уширению ЛПР на

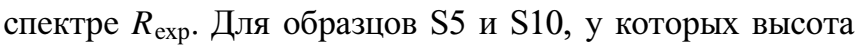
и поперечные размеры наночастиц относительно небольшие, наблюдаются провалы при $\lambda=331$ и $338 \mathrm{~nm}$.

Далее на рис. 6 представлено сравнение экспериментальных спектров между собой для нормального и наклонного углов падения света. Для образца S1 форма спектра для обоих углов в УФ области (до $430 \mathrm{~nm}$ ) одинакова, а для $\lambda>450 \mathrm{~nm}$ изменяется незначительно. При этом сохраняется провал ЛПР с минимумом при $382 \mathrm{~nm}$. Для образца S5 при $\varphi=45^{\circ}$ наблюдается уменьшение значений $R_{\exp }$ с параллельным сдвигом на $\Delta R=0.06-0.09$, за исключением диапазона $\lambda=250-280 \mathrm{~nm}$. В УФ области наблюдается провал с минимумом около $\lambda \sim 335 \mathrm{~nm}$ при наклонном угле. Учитывая близость этого минимума к расчетному положению объемного плазмона в продольной моде для спектра $p$-поляризации сплошной пленки $\mathrm{Ag}$ при $\lambda \sim 323 \mathrm{~nm}$ (рис. 4), можно отнести полученные провалы на экспериментальных спектрах для слоев наночастиц Ag S5 и S10 к этому типу особенностей.

Таким образом, измерения при двух углах падения показывают хорошо сопоставимые оптические особенности по трем образцам слоев наночастиц Ag разной морфологии. Интерпретацию спектров дополняет предварительный расчет в рамках модели сплошной пленки $\mathrm{Ag}$ по мере роста ее толщины с предсказанием оптических особенностей, характерных для структуры с объемными характеристиками диэлектрических функций.

\section{Выводы}

Исследованы спектры отражения $R$ для нормального и наклонного углов падения света на слои наночастиц $\mathrm{Ag}$, осажденных на поверхности $\mathrm{Si}$ из раствора $\mathrm{AgNO}_{3}$. Измерения при двух углах падения показывают хорошо сопоставимые оптические особенности по трем образцам слоев наночастиц $\mathrm{Ag}$ разной морфологии. Для образца S1 структура слоя наночастиц, несмотря на несплошность, проявляет в УФ области оптические свойства, близкие к $\mathrm{Ag}_{\text {bulk, }}$, а в спектре отражения в 
видимой области наблюдается локализованный плазмонный резонанс, а также влияние оптических особенностей (КТ) подложки.

Для образцов S5 и S10, имеющих близкие по форме спектры $R$, в УФ диапазоне видны оптические особенности подложки в виде обеих КТ, объясняемые небольшой толщиной слоев, которые также видны в расчетных спектрах для сплошных пленок $\mathrm{Ag}$ для таких же толщин. Для этих образцов провал, связанный с межзонными переходами, на спектрах $R_{\exp }$ для обоих углов падения отсутствует, так как осажденные наночастицы $\mathrm{Ag}$ не сформировались в структуру с оптическими свойствами объемного Ag, но проявился провал, интерпретируемый как объемный плазмонный резонанс в продольной моде при наклонном угле падения.

\section{Благодарности}

Авторы благодарят Д.П. Щербинина за проведение измерений спектров отражения для наклонного угла падения, Е.В. Гущину за измерение толщины слоев наночастиц $\mathrm{Ag}$ и С.И. Павлова за РЭМ-изображения, полученные в ЦКП при ФТИ им. Иоффе.

\section{Конфликт интересов}

Авторы заявляют, что у них нет конфликта интересов.

\section{Список литературы}

[1] Kreibig U., Vollmer M. Optical Properties of Metal Clusters. Berlin: Springer, 1995. 576 p.

[2] Stefan A. Maier. Plasmonics: Fundamentals and Applications. N Y:: Springer Science+Business Media LLC, 2007. 223 p.

[3] Климов В.В. Наноплазмоника. М.: Физматлит, 2009. 480 с.

[4] Балыкин В.И // УФН. 2018. Т. 188. № 9. С. 935. doi 10.3367/UFNr.2017.09.038206

[5] Hilgerm A., Tenfeldeu M., Kreibig U. // App. Phys. B. 2001. V. 73. P. 361. doi $10.1007 / \mathrm{s} 003400100712$

[6] Кособукин В.А. // ФТТ. 2012. Т. 54. № 12. С. 2340.

[7] Gladskikh P.V., Gladskikh I.A., Toropov N.A., Vartanyan T.A. // Proc. of SPIE. 2016. V. 9884. P. 98842Y. doi org/10.1117/12.2227597

[8] Jo de Vries A., Kooij E.S., Wormeester H., Mewe A.A., Poelsema B. // J. Appl. Phys. 2007. V. 101. P. 053703. doi $10.1063 / 1.2654234$

[9] Marsillac S., Little S.A., Collins R.W. // Thin Solid Films. 2011. V. 519. P. 2936. doi 10.1016/j.tsf.2010.11.065

[10] Oates T.W.H., Wormeester H., Arwin H. // Progress in Surface Science. 2011. V. 86. P. 328. doi 10.1016/j.progsurf.2011.08.004

[11] Жарова Ю.А., Толмачев В.А., Бедная А.И., Павлов С.И. // ФТП. 2018. Т. 52. № 3. Р. 576.

[12] Handbook of Optical Constants of Solids / Ed. by Palik E.D. N Y.: Academic Press, 1985. P. 804.

[12] Aspnes D.E. // Thin Solid Films. 1982. V. 89. P. 249.

[13] Doremus R. // Thin Solid Films. 1998. V. 326. P. 205.

[14] MacAlister A.J., Stern E.A. // Phys. Rev. 1963. V. 132. N 4. P. 1599.
[15] Yang H.U., D'rchangel J., Sundheimer M.L., Tucker E., Boreman Glenn D., Raschke M.B. // Phys. Rev. B. 2015. V. 91. P. 235137.

[16] Leveque G., Olson C.G., Lynch D.W. // Phys. Rev. B. 1983. V. 24. P. 4654.

[17] Winsemius P., van Kampen F.F., Lengkeek H.P., van Went C.G. // J. Phys. F: Met. Phys. 1976. V. 6. P. 1583.

[18] Wang Y., Plummer E. W., Kempa K. // Advances in Physics. 2011. V. 60. P. 799. 